\title{
Suicidal behaviour and the menstrual cycle
}

\author{
KATE E. A. SAUNDERS ${ }^{1 *}$ AND KEITH HAWTON ${ }^{2}$ \\ ${ }^{1}$ Warneford Hospital, Oxford, UK ${ }^{2}$ Centre for Suicide Research, Oxford University Department of Psychiatry, \\ Warneford Hospital, Oxford, UK
}

\begin{abstract}
Background. To investigate the available data regarding possible associations between phases of the menstrual cycle and suicidal behaviour.

Method. A systematic search of major relevant databases was performed using appropriate search terms.

Results. Forty-four relevant studies were identified in total, 13 pertaining to suicide, two pertaining to both attempted and completed suicide, 23 to suicide attempts, three to suicide attempts in those suffering from the premenstrual syndrome (PMS), three to suicidal ideation and two to repetitive self-harming behaviours. A variety of methodologies were used in these studies and there were notable differences in the conclusions reached. Studies with better methodology suggest that a positive relationship exists between aspects of the menstrual cycle and non-fatal suicidal behaviour. Such behaviour appears to be more common in those phases of the menstrual cycle when oestrogen levels are lowest (the late luteal and follicular phases), and in those suffering from PMS.
\end{abstract}

Conclusions. There appears to be an association between the menstrual cycle and non-fatal suicidal behaviours. Interaction between oestrogen and the serotonergic system may provide a possible mechanism.

\section{INTRODUCTION}

Suicide accounts for $7 \cdot 1 \%$ of deaths world-wide in females aged 15-44 years, being second only to tuberculosis as a single leading cause of death in this group (WHO, 1999). However, far fewer women commit suicide than men, although they are two to three times more likely to attempt suicide. Early references to suicidal tendencies and menstrual function are found in Hippocrates ('On the diseases of maidens', see Craik, 1998, pp. 1-11), who described the wandering womb as the major cause of female madness and misery. Esquirol, the nineteenthcentury French psychiatrist, described suppression of the menses as a cause of insanity

\footnotetext{
* Address for correspondence: Dr Kate Saunders, Warneford Hospital, Oxford, OX3 7JX, UK.

(Email: kate.saunders@oxmhc-tr.nhs.uk)
}

'terminated by re-establishment of the menstrual flux' (Esquirol, 1885). Freud (1978 [1883-1895]) focused intensively on this issue. The effect of menstruation on suicide was first put forward in 1864, when suicide resulting from catamenial insanity was reported in Boston (Storer, 1864).

The menstrual cycle has continued to be considered by some to be relevant to suicidal behaviour because of associations with disturbances in mood. The initiation of the menarche coincides with the beginning of gender-based differences in the rates of mood disorder (Kessler et al. 1993) and the cyclical fluctuations in ovarian steroids are thought to bear some relationship to the vulnerability of women to depression (Nolen-Hoeksema, 1987). The menarche is also the time when gender differences in self-harming behaviour become manifest, this behaviour being very much more 
prevalent in young adolescent girls than boys (Hawton et al. 2003a).

We have conducted a systematic review of the research literature on the menstrual cycle and suicidal behaviours, and analysed the results in order to assess the evidence for a possible causal association, to determine the influence of methodological differences on the findings, and to investigate possible mechanisms for any relationship.

\section{METHOD}

A literature search of Medline 1966-2005/06, Biological Abstracts 1985-2005, Embase 19802005/06 and PsychInfo 1872-2005/06 was conducted using the following search terms: (menstrual cycle or menstruation) and suicide; (menstrual cycle or menstruation) and suicidal ideation; (menstrual cycle or menstruation) and suicidality; (menstrual cycle or menstruation) and attempted suicide; (menstrual cycle or menstruation) and parasuicide; (menstrual cycle or menstruation) and self-harm. References in identified papers were followed up. Experts in the field were also contacted. No language restrictions were applied to the search. Data were extracted from studies by K.E.A.S. Metaanalysis of data was not considered feasible because of the wide heterogeneity in the design of the studies. Therefore, review of the findings is largely descriptive.

\section{RESULTS}

In presenting the results we have grouped them into those pertaining to suicide, attempted suicide, self-harm and suicidal ideation. We have also included a separate section on suicidal behaviour and the premenstrual syndrome (PMS).

\section{Suicide}

Thirteen papers concerning suicide and the menstrual cycle were identified from the literature search (Table 1). Two further papers investigated both suicide and attempted suicide (Peller, 1935; von Balazs, 1936).

Early studies reported that between $35 \%$ and $100 \%$ of women committing suicide were menstruating [Heller, 1900; Ollendorf, 1905 (cited in Wetzel et al. 1971); Pilcz, 1905 (cited in Wetzel et al. 1971); Slavik, 1909; Sachwiz, 1927; Elo,
1931; Babin, 1933]. MacKinnon \& MacKinnon (1956) carried out autopsies on 23 women whose deaths were given a coroner's verdict of suicide. They found suicides were more frequent during the mid-luteal phase of the cycle. However, the same distribution was found for women who died from accidents and diseases. Ribeiro (1962) studied the bodies of 22 Hindu women discovered self-immolated in a mass grave and found that 19 were menstruating, while two others were pregnant.

Later studies provide more methodological detail but came to negative conclusions. Helweg-Larsen \& Hestbech (1985) examined endometrial tissue from 35 fertile women who had died due to suicide or accident, and found no correlation between manner of death and endometrial phase. A much larger study was carried out by Vanezis (1990). Of 257 consecutive endometrial samples sent for coroner's autopsy, 86 were discarded (see below) and the tissue from the remaining 171 women examined. Of the 50 that died by suicide, 26 were in the menstrual phase, 67 in the proliferative phase, 29 in the early secretory phase, and 49 in the $\mathrm{mid} /$ late secretory phase. While somewhat fewer women were in the mid/late secretory phase, the difference was not significant.

Methodology is key to interpreting these studies. Problems lie primarily in tissue storage and examination. Endometrial tissue autolyses rapidly after death so fresh specimens with rapid fixation are essential. The endometrial phase can be determined macroscopically and microscopically. In macroscopic studies researchers must consider whether the uterus was grossly congested, as autolysing cells can easily be confused with those from a menstruating uterus. Congestion is common in many types of death, especially hanging, due to the distribution of hypostasis.

In the study by Helweg-Larsen \& Hestbech (1985) there was a variable period of 2 to 7 days between time of death and autopsy. As a consequence, $49 \%$ of their cases had to be excluded because of tissue autolysis. Vanezis (1990), by contrast, carried out all autopsies within 48 hours, reducing exclusions to $26 \%$. HelwegLarsen \& Hestbech also controlled for interexaminer variability, having two separate examiners for each sample. The two examiners only agreed in $62 \%$ of cases. 
Table 1. Studies of suicide and menstrual cycle phase

\begin{tabular}{|c|c|c|c|c|c|c|}
\hline Author & Date & Patient selection & No. & Sample & Cycle phase & Result \\
\hline Heller & 1900 & Pathology Institute & 70 & 50 & N.R. & $50 \%$ menstruating \\
\hline Ollendorf ${ }^{\mathrm{a}}$ & 1905 & $\begin{array}{l}\text { State Medical Research } \\
\text { Institute }\end{array}$ & 79 & 48 & N.R. & $35 \%$ menstruating \\
\hline Pilcz $^{\mathrm{a}}$ & 1905 & Pathology Institute & 426 & 155 & N.R. & $\begin{array}{l}15 \% \text { menstruating } \\
34 \% \text { premenstrual }\end{array}$ \\
\hline Slavik & 1909 & N.R. & 474 & 474 & N.R. & $33 \%$ menstruating \\
\hline Elo & 1931 & Police cases & 187 & 147 & & $29 \%$ menstruating \\
\hline Babin & 1933 & Equivocal cases autopsied & 20 & 17 & N.R. & $29 \%$ menstruating \\
\hline Bruchter ${ }^{b}$ & N.A. & N.R. & 86 & 86 & N.R. & $23 \%$ menstruating \\
\hline Krugelstein ${ }^{\mathrm{b}}$ & N.A. & N.R. & 107 & 107 & N.R. & $100 \%$ menstruating \\
\hline MacKinnon et al. & 1959 & Women given suicide verdict & 23 & 23 & Follicular, early/mid/late luteal & Rate greatest in luteal phase \\
\hline Ribeiro & 1962 & Hindu women in a mass grave & 22 & 22 & N.R. & 19 of 22 were menstruating \\
\hline $\begin{array}{l}\text { Helweg-Larsen } \\
\text { \& Hestbech }\end{array}$ & 1985 & $\begin{array}{l}\text { Female deaths due to suicide } \\
\text { and accidents }\end{array}$ & 57 & 35 & Divided into four phases & No correlation \\
\hline \multicolumn{7}{|l|}{$\begin{array}{l}\text { Suicide and } \\
\text { attempted suicide }\end{array}$} \\
\hline Peller & 1935 & $\begin{array}{l}\text { Suicide/suicide attempters } \\
\text { admitted to medical wards }\end{array}$ & 899 & 864 & N.R. & $11 \%$ menstruating \\
\hline von Balazs & 1936 & $\begin{array}{l}\text { Suicide/suicide attempters } \\
\text { admitted to medical wards }\end{array}$ & 3110 & 3110 & N.R. & $\begin{array}{l}23 \% \text { menstruating, } 41 \% \\
\text { in luteal phase }\end{array}$ \\
\hline
\end{tabular}

\footnotetext{
N.R., Not recorded; N.A., not available.

a Cited in Wetzel et al. (1971).

b Cited in von Balazs (1936).
}

Comparison of the studies is difficult, especially as those reporting a relationship between suicide and menstrual cycle phase lacked methodological information. In addition, most studies had small sample sizes. Overall, it can be concluded that an association between suicide and the phase of the menstrual cycle has not been proven.

\section{Attempted suicide}

Twenty-three studies investigating attempted suicide and menstrual cycle phase were found (Table 2). Fifteen of these reported a positive association. Assimilating the findings is difficult as authors divided the menstrual cycle in different ways. Dalton (1959) examined the admission records of two large mental hospitals and a mental observation ward. She found that the highest incidence of acute psychiatric crisis, attempted suicides and depressive illness was during the early menstrual phase, with a subsidiary peak during the premenstrum. Trautman (1961) also reported an increase during menstruation. Tonks et al. (1968) reported a slightly different profile. Attempted suicide was more common during menstrual and luteal phases than during the rest of the cycle, endorsing the findings of Jannone (1962) and Zacco et al. (1960) a few years earlier. Glass et al. (1971) studied emergency psychiatric admissions and found over that $75 \%$ who had made a suicide attempt were premenstrual. These findings were upheld by Parvathi Devi and Venkoba Rao (1972), who found that $64 \%$ of women admitted to hospital for attempted suicide were premenstrual.

Baca-Garcia et al. $(2003 a, 2004)$ conducted two prospective naturalistic studies of female patients admitted to a general hospital in Madrid. In both studies they found that the incidence of suicide attempts was significantly higher in the first week of the menstrual cycle. They found that this association between suicidality and menstrual phase held for both methodologies they used (patient reporting and blood hormone levels).

No association between menstrual cycle phase and suicide attempts was reported in eight studies. Buckle et al. (1965) included menstrual cycle phase in their study of the characteristics 
Table 2. Studies of suicide attempts and menstrual cycle phase

\begin{tabular}{|c|c|c|c|c|c|c|c|c|c|}
\hline Author & Date & Patient selection & No & Sample & $\begin{array}{l}\text { Definition of } \\
\text { suicide attempt }\end{array}$ & Method & Type of cycle & Cycle phases & Result \\
\hline Steiner & 1926 & $\begin{array}{l}\text { Admission to medical } \\
\text { wards }\end{array}$ & 39 & 39 & & $100 \%$ poison & N.R. & N.R. & $\begin{array}{l}28 \% \text { menstruating, } \\
28 \% \text { premenstrual }\end{array}$ \\
\hline Dalton & 1959 & $\begin{array}{l}\text { Psychiatric hospital } \\
\text { admission }\end{array}$ & 36 & 36 & N.R. & N.R. & $\begin{array}{l}\text { Cycle duration } \\
<28 \text { days }\end{array}$ & $\begin{array}{l}\text { Divided into seven } \\
\text { 4-day phases }\end{array}$ & $39 \%$ menstruating \\
\hline Zacco et al. & 1960 & Hospital admissions & 225 & 225 & N.R. & N.R. & N.R. & N.R. & $\begin{array}{l}3 \% \text { menstruating, } \\
54 \% \text { luteal }\end{array}$ \\
\hline Trautman & 1961 & $\begin{array}{l}\text { Hispanics admitted for } \\
\text { suicide attempts at a } \\
\text { general hospital }\end{array}$ & 50 & 47 & N.R. & Self-poisoning & N.R. & $\begin{array}{l}\text { Menstruation, } \\
\text { premenstrual ( } 3 \text { days } \\
\text { before menstruation), } \\
\text { postmenstrual ( } 3 \text { days } \\
\text { after menstruation) }\end{array}$ & $34 \%$ menstruating \\
\hline Jannone & 1962 & Hospital admissions & 22 & 20 & N.R. & Self-poisoning & N.R. & N.R. & $\begin{array}{l}5 \% \text { menstruating, } \\
70 \% \text { luteal }\end{array}$ \\
\hline Buckle et al. & 1965 & Emergency room & 64 & 55 & $\begin{array}{l}\text { Overdosing or } \\
\text { inflicting } \\
\text { bodily harm }\end{array}$ & $95 \%$ self-poisoning & N.R. & $\begin{array}{l}\text { Menstrual phase (1-5 } \\
\text { days) and ovulatory } \\
\text { phase (13-16 days) }\end{array}$ & No relationship \\
\hline Janowsky et al. & 1967 & Hospital admissions & 90 & 44 & N.R. & N.R. & $\begin{array}{l}\text { Regular cycles, } \\
15-40 \text { years }\end{array}$ & $\begin{array}{l}\text { Menstrual phase (1-5 } \\
\text { days), premenstrual } \\
\text { phase lasted } 5 \text { days }\end{array}$ & $\begin{array}{l}\text { Similar distribution to } \\
\text { other admissions with } \\
\text { a premenstrual excess }\end{array}$ \\
\hline Tonks et al. & 1968 & $\begin{array}{l}\text { General hospital } \\
\text { admissions }\end{array}$ & 95 & 95 & $\begin{array}{l}\text { Acts of deliberate } \\
\text { self-injury }\end{array}$ & N.R. & $\begin{array}{l}\text { Regular cycles, } \\
15-40 \text { years }\end{array}$ & $\begin{array}{l}\text { Menstruation ( } 1-5 \\
\text { days), premenstrual } \\
\text { (22-28 days), } \\
\text { ovulation ( } 11-16 \text { days) }\end{array}$ & $\begin{array}{l}22 \% \text { menstruating, } \\
36 \% \text { luteal }\end{array}$ \\
\hline Glass et al. & 1971 & $\begin{array}{l}\text { Emergency room in a } \\
\text { psychiatric hospital }\end{array}$ & 166 & 13 & N.R. & N.R. & $\begin{array}{l}\text { Active natural cycle for } \\
3 \text { months preceding }\end{array}$ & $\begin{array}{l}\text { Menstruation } \\
\text { (1st week), midcycle } \\
\text { (2nd-3rd week), } \\
\text { premenstrual phase } \\
\text { (4th week) }\end{array}$ & $77 \%$ premenstrual \\
\hline $\begin{array}{l}\text { Parvathi Devi \& } \\
\text { Venkoba Rao }\end{array}$ & 1972 & Hospital admissions & 115 & 72 & N.R. & N.R. & Regularly menstruating & $\begin{array}{l}\text { Divided into three } \\
\text { phases }\end{array}$ & $64 \%$ premenstrual \\
\hline Holding \& Minkoff & 1973 & $\begin{array}{l}\text { Regional Poisoning } \\
\text { Centre }\end{array}$ & 186 & 74 & N.R. & $\begin{array}{l}93 \% \text { self-poisoning, } \\
3 \% \text { self-injury, } \\
4 \% \text { both }\end{array}$ & $\begin{array}{l}\text { Cycle duration } 21-35 \\
\text { days, no contraceptive } \\
\text { pill }\end{array}$ & $\begin{array}{l}\text { Divided into two 14-day } \\
\text { phases, Divided into } \\
\text { seven 4-day phases }\end{array}$ & No relationship \\
\hline Birtchnell \& Floyd & 1974 & $\begin{array}{l}\text { All those entering A\&E } \\
\text { regardless of whether } \\
\text { they were retained }\end{array}$ & 107 & 76 & N.R. & $\begin{array}{l}\text { Self-poisoning } \\
\text { and self-injury }\end{array}$ & $\begin{array}{l}\text { Regular cycle, no } \\
\text { contraceptive use }\end{array}$ & N.R. & No relationship \\
\hline Pallis \& Holding & 1976 & $\begin{array}{l}\text { Emergency dept of two } \\
\text { DGHS }\end{array}$ & 255 & 114 & $\begin{array}{l}\text { Self-poisoning/ } \\
\text { self-injury }\end{array}$ & $93 \%$ self-poisoning & $\begin{array}{l}\text { Regular cycle } 21-35 \\
\text { days, no OC use }\end{array}$ & $\begin{array}{l}1-4,25-28,1-7,21-28 \\
1-14,15-28,1-7,8-21 \\
22-28,1-14,15-28, \\
17-23 \text { days }\end{array}$ & No relationship \\
\hline Luggin et al. & 1984 & $\begin{array}{l}\text { Admissions at a county } \\
\text { hospital }\end{array}$ & 358 & 121 & N.R. & N.R. & $\begin{array}{l}\text { Duration } 21-25 \text { days, } \\
\text { no OC use, age } \\
25-45 \text { years }\end{array}$ & $\begin{array}{l}\text { Four equal-length } \\
\text { phases }\end{array}$ & No relationship \\
\hline Forestié et al. & 1986 & $\begin{array}{l}\text { Emergency dept of } \\
\text { hospital }\end{array}$ & 123 & 108 & N.R. & $95 \%$ self-poisoning & $\begin{array}{l}\text { Young with regular } \\
\text { cycles and no } \\
\text { hormonal therapy }\end{array}$ & $\begin{array}{l}1-7,8-14,15-21,22-28 \\
>28 \text { days }\end{array}$ & $41 \%$ 1st week \\
\hline
\end{tabular}



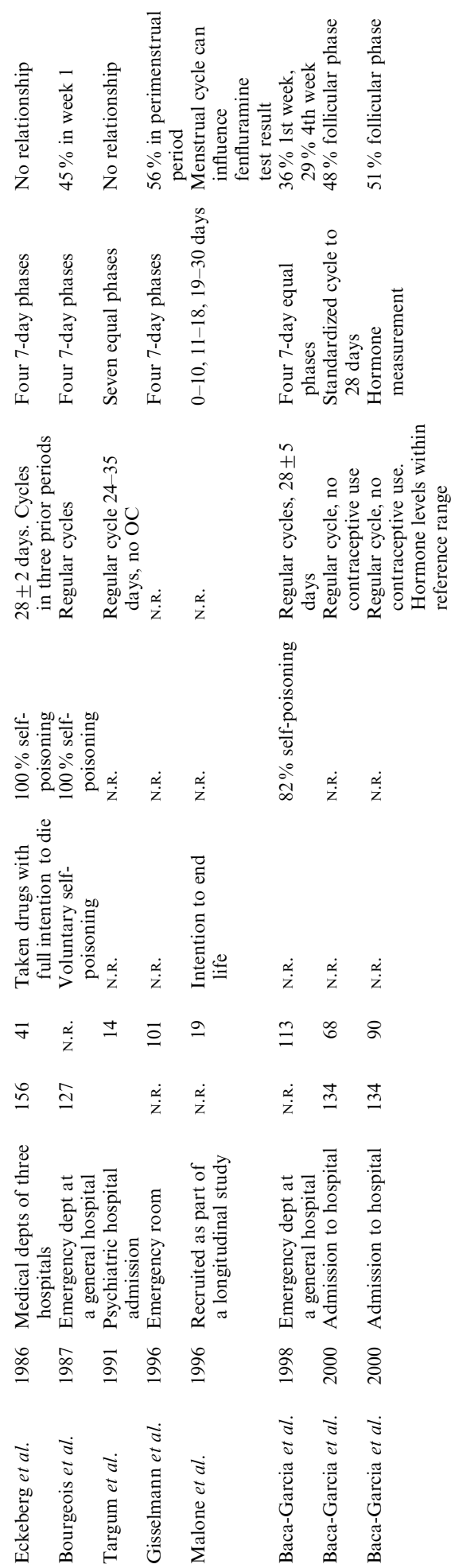

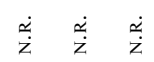

$\cong \approx \&$

$\stackrel{\dot{q}}{\ddot{m}} \stackrel{ \pm}{=}$

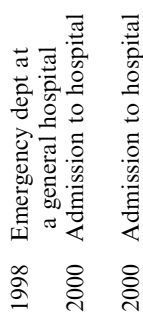

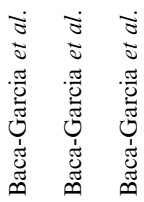

of suicide attempters and found it bore no relation to suicidal behaviour. Two studies (Holding \& Minkhoff, 1973; Eckeberg et al. 1986) examined consecutive admissions after attempted suicide and failed to find a relationship. Birtchnell \& Floyd (1974) compared their observed distribution of suicide attempts with a calculated expected distribution that took into account variability of cycle length and found there was no significant difference between the two. Two studies (Luggin et al. 1984; Targum et al. 1991) examined the relationship of menstrual cycle phase to admission to psychiatric hospital. Both concluded that there did appear to be some correlation between menstrual cycle phase and risk of acute psychiatric admission, but that there was no difference between those admitted after suicide attempt and any other psychiatric presentation leading to hospitalization.

Although studies have included a number of background variables, few have focused on objective indices of suicidal intent (wish to die). A scale for rating suicidal intent was devised and validated by Beck et al. $(1974 a, b)$. Pallis \& Holding (1976) used the Beck Suicide Intent Scale to evaluate the suicidal intent of women admitted to hospital after attempted suicide. They found women making their suicide attempts in the premenstrual week had significantly higher suicidal intent, but no differences in age, marital status, depressive symptom score or premenstrual symptom score. Holding \& Minkhoff (1973) found no relationship to the phase of the menstrual cycle in parasuicide admissions to a regional poisoning treatment centre after controlling for age, suicidal intent, marital status and premenstrual scores.

Overall, it is difficult to draw any firm conclusions but there does seem to be limited evidence to suggest that suicide attempts are more common in the first week of the menstrual cycle.

\section{Premenstrual syndrome (PMS)}

In women with PMS and psychiatric disorder, suicide attempts have been recorded in 15-20\% (Clare, 1983; Keye et al. 1986; Stout et al. 1986). Endicott \& Halbreich (1988) found that women who report premenstrual dysphoric changes were more likely to have had prior episodes of major depressive disorder, and women who were currently depressed tended to have premenstrual exacerbations or changes in their symptoms. 
This increased risk of depressive crises was associated with an increased likelihood of admission to both out-patient and in-patient psychiatric facilities during the few days before or just after the onset of the menses (Abramowitz et al. 1982). Stout et al. (1986) found a discrepancy between the low numbers of women with PMS meeting the criteria for major depressive disorders and the high number of women reporting suicidal ideation and attempts, suggesting that women seeking treatment for PMS may be reluctant to admit to more continuous depression because of an awareness of the selflimiting nature of their symptoms. Another possibility is that their depressive symptoms are shorter but more intense. However, Stout et al. (1986) found elevated levels of DSM-III criteria for dysthymia, obsessive-compulsive disorder, alcohol abuse/dependence and drug abuse/ dependence in these women. Whatever the explanation, the number of suicide attempts indicates that women who seek treatment for PMS are a high-risk group.

Chaturvedi et al. (1995) examined the relationship between suicidal ideation and psychological symptoms of PMS. They found symptoms of irritability, mood swings and depression were more frequently reported by women with suicidal ideas during the premenstrual period. They also noted significant differences in rates of suicidal ideation in women from different social backgrounds, indicating a likely influence of social factors. By contrast, recent work by Baca-Garcia et al. (2004) suggests that premenstrual dysphoric disorder (PMDD) may not be associated with suicidal acts during the luteal phase, when premenstrual symptoms are present. However, this study was limited by the use of retrospective PMDD diagnosis.

Overall, there appears to be a significant association between PMS and suicide attempts.

The current recommended treatment for PMS is selective serotonin reuptake inhibitors (SSRIs). A systematic review has shown these to be effective in treating both physical and behavioural symptoms (in which the authors include psychological symptoms), and their mechanism of action appears to be different to that in depression (Baca-Garcia et al. 2004). None of the 15 treatment trials reviewed by Wyatt et al. (2003) looked specifically at changes in suicidal behaviour.

\section{Repetitive self-harm}

Few studies have examined the relationship between the menstrual cycle and repetitive selfharming behaviour. Menstrual and behavioural records of nine women with mental retardation who exhibited repetitive self-harming behaviour were analysed for 6 months to determine the association of rates of such behaviour and menstrual cycle phase (Taylor et al. 1993). Analysis showed that the highest frequency of this behaviour was during the early and late follicular phases. Seven of the women exhibited cyclical self-harming behaviours and manifested identical menstrual phase relations. However, no firm conclusions can be reached given the very small and specific subject group.

Assuming suicidal behaviours are related to the inability to regulate painful emotions, the menstrual cycle may have some bearing on repetitive self-harming behaviours, given the emotional changes associated with the cycle and the mood regulating function of the behaviour. Rosenthal et al. (1972) reported that $65 \%$ of self-cutters had a negative reaction to menarche and were disturbed at menstruation. More than $60 \%$ of cutting episodes occurred during the menses. Over half the women had menstrual irregularities with frequent amenorrhoea, the most deviant patterns being displayed by the habitual cutters. None of the patients had exhibited cutting behaviours before the onset of the menarche. Simpson (1975) looked at those presenting to hospital as a result of self-cutting and found that $70 \%$ reacted negatively to the menses. However, we could find no other studies where repetitive self-harm and the menstrual cycle have been investigated.

\section{Suicidal ideation}

Three studies were found that examined the possible association between the menstrual cycle and suicidal ideation. All reported a positive relationship. Mandell \& Mandell (1967) examined calls to the Los Angeles Suicide Prevention centre. Of 112 calls, 87 were included. Exclusion criteria included pregnancy, not yet menstruating, perimenopausal, hysterectomy and insufficient information. Most calls occurred during the menstrual phase, followed by the premenstrual phase with a midcycle rise. 
Wetzel et al. (1971) carried out a similar study of calls to Suicide Prevention Inc. in St Louis. They also recorded self-judged lethality. Of 181 women who called during the study period, only 56 could be assigned to a phase of the menstrual cycle using the same method as Mandell \& Mandell. They found that double the expected number of women called during the menstrual phase, with no increase during ovulation or in the late luteal phase. Self-judged lethality was also significantly related to position in the cycle, with $57 \%$ of those in the luteal or menstrual phases reporting that they had seriously considered suicide on the day of the call, compared with $23 \%$ in the follicular phase. Of those who had previously attempted suicide, just $20 \%$ reported having seriously considered suicide that day compared with $77 \%$ of those who called in the menstrual and luteal phases. Only a small number of the total callers were studied so the results may be biased. Telephone workers had a primary obligation to provide a service to the caller and had been informed in advance of the findings of MacKinnon et al. (1959), so callers in the luteal phase about whom the volunteer was especially concerned were more likely to have been referred for help immediately rather than included in the study. The authors failed to describe how suicidal ideation was established and selection was dependent on the telephone worker's willingness to participate, and judgement of the caller's suitability for interview.

\section{DISCUSSION}

Investigation of the possible relationship between the menstrual cycle and non-fatal suicidal phenomena is subject to several major methodological issues. These may explain the inconsistencies in many of the findings. Here we focus on non-fatal suicidal phenomena as the methodological issues regarding suicide were considered earlier.

\section{Definition of behaviour}

Considerable debate surrounds the correct nomenclature of suicidal behaviour (O'Carroll et al. 1996). In the studies that have looked at suicide attempts and the menstrual cycle, just over a quarter provided a clear definition of the behaviour (Table 2). Differences in definition may have contributed to variations in study findings.

\section{Study samples}

The representative nature of study samples is another issue. The majority of studies excluded a significant proportion of the initial sample group. Exclusion criteria included pregnancy, menopause, hormone therapy, amenorrhoea, cycles longer than 32 days, inability to remember date of last menstrual phase and irregular cycles. Substantial subsamples of women were therefore excluded, which may have influenced the findings. In addition, relatively small sample sizes meant that in most studies it was not possible to control for the influence of sociodemographic data or clinical variables such as mood disorder. However, as there was little disparity between the sample sizes in studies that found a relationship between suicidal behaviour and menstrual cycle phase and those that did not, this is unlikely to account for the contradictory results.

\section{Timing of assessment}

Timing of enquiry is crucial when the objective marker of the research is menstrual phase, but less than $50 \%$ of studies reported the interval between the suicide attempt and assessment of the phase of the menstrual cycle. All studies relied on patient reporting for the date of the last menstrual period and thus the time course of the rest of the cycle. Women are notoriously poor at accurately reporting where they are in the cycle, although there is no evidence that the psychiatrically ill are any less accurate than the well (Thompson et al. 1997). Enquiry into cycle phase in the studies took place soon after the suicide attempts, when memory may have been clouded by the persisting effects of, for example, an overdose (almost all suicide attempts studied were by overdose) or level of distress.

\section{Identification of menstrual cycle phase}

The variable duration of the cycle and the hormonal influences upon it mean that it is rarely possible to predict the date of onset of menstruation precisely or localize events within the cycle. The adjustment of the cycle to an ideal 28 days introduces errors. None of the methods used accounted for the fixed duration of the luteal phase. It is generally agreed that the 


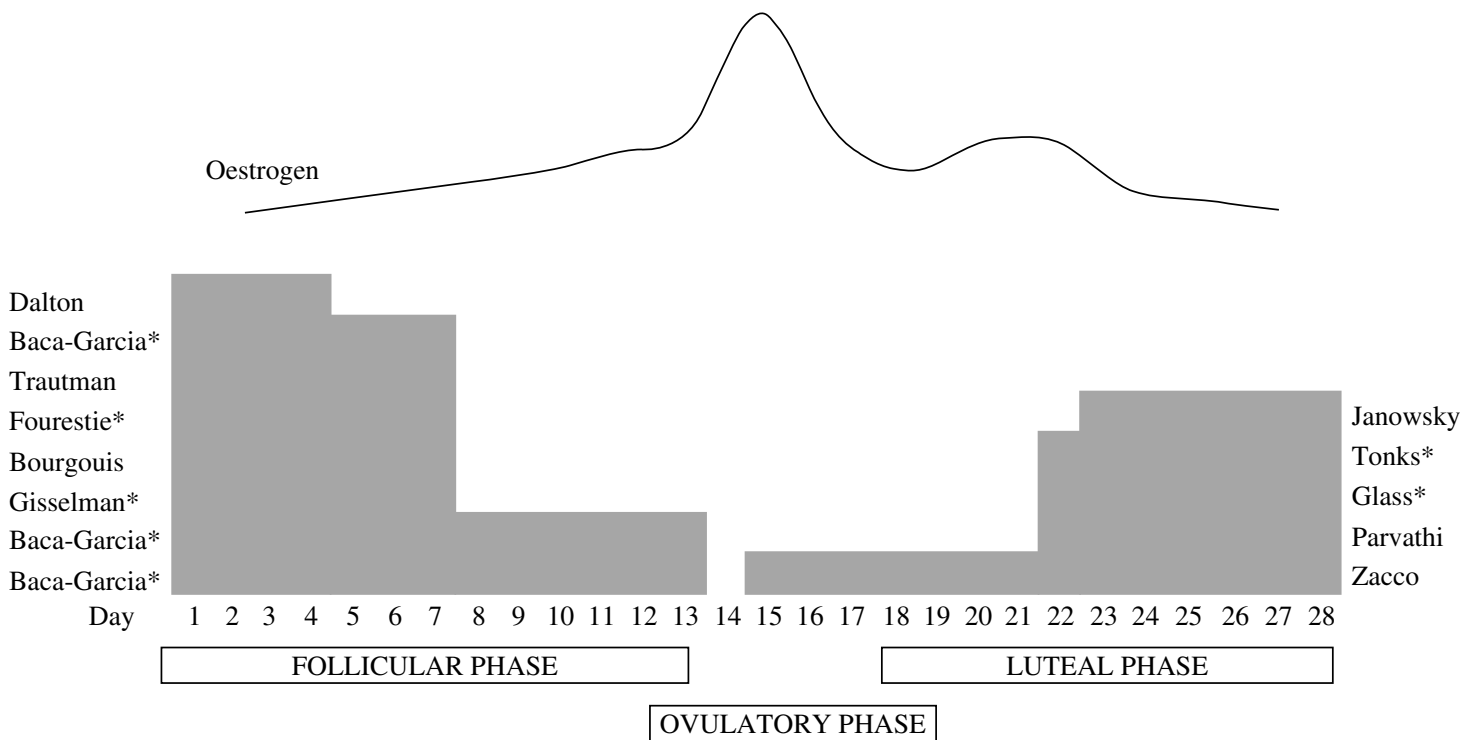

FIG. 1. Phases of the menstrual cycle positively correlated with suicide attempts and changes in oestrogen concentration during the cycle. * Denotes studies where results were statistically significant.

lifetime of the corpus luteum is fairly constant in all women, so this needs to be considered when attempting to normalize cycles for comparison.

Tonks et al. (1968) used 28 days as the length of the cycle for all women regardless of whether they reported longer cycles. This artificially increases the number of patients supposedly attempting suicide on the 28th day. Dalton (1959) excluded all women with amenorrhoea exceeding 28 days. This led to the inclusion of those with cycles greater than 28 days who were in the early part of their cycle, creating a misleading excess of patients attempting suicide at this stage. Some authors used a standardized cycle. This involved dividing the number of days from the start of the cycle by the total length of the cycle and multiplying by seven, allowing subjects to be placed into one of seven positions, creating an artificial 28-day cycle. This method is also flawed, however, as ovulation does not necessarily occur at mid-cycle.

Baca-Garcia et al. (2000) explored how the effects of two methodological issues (sample selection and assessment of menstrual cycle phases) might contribute to the inconsistent published results. They used the same selection criteria that had been used in the majority of studies. Exclusion criteria were menopause, hormone therapy, hormone levels beyond the reference range, irregular cycles and technical reasons. Further selection then occurred for each assessment method used. Cycle phase was assessed by two clinical methods and by a single serum hormone measurement. The sample size for hormonal assessment was $69 \%$ of the original sample group, which is considerably greater than in the majority of previous studies.

Taking hormonal measurement as the reference standard, the methods based on patient reporting did not seem reliable enough to estimate menstrual cycle phases, with only approximately two-thirds concordance between patient reporting and hormonal measurements (BacaGarcia et al. 2000). Single hormone samples may limit accuracy of phase ascertainment because of the pulsatile nature of gonadotrophin secretion but others argue that single measurements of serum oestradiol peak has high positive predictive value $(83 \%)$ and negative predictive value $(100 \%)$ when used to predict ovulation (Grinsted et al. 1989). It can be argued that sample hormone levels need to be taken over at least two cycles to accurately assess cycle position because gonadotrophins are secreted in a pulsatile, diurnal pattern. 


\section{Pharmacological influences}

The influence of psychotropic medicines on the menstrual cycle may be a further relevant factor, especially because many individuals who attempt suicide are receiving psychotropic medication (Hawton et al.2003a). Antipsychotics are known to influence the cycle (Carter et al. 1982) but benzodiazepines and antidepressants are probably less important. It is unclear whether those who experience cycle disturbance secondary to such medications are excluded from the majority of studies for this reason.

Any interpretation of a possible relationship between suicide and the menstrual cycle needs to consider cycle-related cyclicity of mood, the neuromodulatory effects of the sex hormones and the possible influence of the PMS.

\section{Mood disturbance}

The initiation of the menarche coincides with the beginning of gender-based differences in rates of mood disorder. However, empirical evidence for cyclicity of mood is equivocal. Some authors have found that the majority of women suffer low mood premenstrually (Moos, 1969; Taylor, 1979; Warner \& Bancroft, 1990), while others have asserted that negative mood peaks in the menstrual phase (EnglanderGolden et al. 1978; Golub \& Harrington, 1981). Furthermore, there are those that that have found no evidence of an association (O'Neil et al. 1984).

\section{Oestrogen levels}

One interesting proposal was that of Forestié et al. (1986), who suggested that suicidal behaviour was related to hypo-oestrogenic phases of the cycle and that the effect of oestrogen over dopamine influences mood in women and thus suicidal behaviour. This was based on an investigation of 108 female suicide attempters within 24 hours of their attempts. They were grouped according to their oral contraceptive (OC) use and plasma levels of oestrogen, progesterone and prolactin were measured. OC non-users had significantly lower plasma oestradiol $(p<$ $0 \cdot 0001)$ at the time of their suicide attempt when compared to a control group, and the majority were in the first or fourth week of the cycle. No significant variation in frequency of suicide attempts was seen in the phases of the menstrual cycle in OC users. Inhibition of ovarian function by OC seemed to eliminate the first week peak seen in the OC non-users. However, BacaGarcia et al. (2000) and Caykoylu et al. (2004) report no difference in follicle stimulating hormone (FSH), luteinizing hormone (LH), oestradiol or progesterone levels between patients who had made a suicide attempt and control subjects.

The fluctuation of ovarian steroids during the menstrual cycle may bear some relationship to the vulnerability of women to suicidal behaviour, or exert effects more directly by modifying neurotransmitter, neuroendocrine or circadian rhythms. Fig. 1 shows the menstrual cycle phases of greatest risk of suicide attempts, based on the findings of this review where a positive association was found. The relevant phases of the cycle clearly correspond to those with lower oestrogen levels.

\section{Serotonin}

Serotonergic function varies during the menstrual cycle, being lower with low levels of gonadal hormones. There is increasing evidence to suggest that oestrogen has a neuromodulatory role (Joffe \& Cohen, 1998). By binding to intracellular receptors, oestrogen mediates a broad range of cellular effects, including transcription of genes acting in the synthesis and metabolism of neurotransmitters, neuropeptides and their receptors, neurotransmitter transporters, nerve growth factors and signal transduction proteins (McEwen et al. 1997). Human studies describing the capacity of oestrogen to modify 5-hydroxytryptamine (5-HT) function are relatively sparse, but studies in female rats suggest that oestrogen may increase 5-HT activity. Cyclical changes in oestrogen concentration during the oestrous cycle increase brain 5-HT receptor concentration (Vitali et al. 1984), 5-HT concentration (Fludder \& Tonge, 1975) and 5-HT binding (Uphouse et al. 1986) during pro-oestrous, the phase when an oestrogen surge is observed. Induction of a hypo-oestrogenic state results in reciprocal changes (Sumner \& Fink, 1995). A pilot human study on a genehormone interaction in female suicide attempters has provided some preliminary evidence that a polymorphism of the serotonin transporter promoter area may protect women from attempting suicide (Baca-Garcia et al. 2003b). 
Overall, female carriers of this polymorphism less often presented to hospital because of attempted suicide than non-carriers but they had lower levels of sex hormones during the menses and menopause, and more often presented to hospital for suicide attempts at these times.

Low serotonergic function appears to increase suicide risk in those with predisposing factors (Mann, 1998). There is suggestive evidence that SSRI antidepressants may decrease suicidal behaviour in low frequency repeaters of self-harm who do not have major depression (Verkes et al. 1998). Biological studies also implicate reduced serotonergic neurotransmission in both outwardly and inwardly aggressive behaviours, especially impulsive acts (Hollander \& Stein, 1995).

\section{Psychological factors}

The aetiology of the relationship between menstrual cycle and self-cutting may differ from that in other suicidal behaviours. A person who attempts suicide seeks to end all feeling whereas a person who repeatedly self-mutilates often does it to feel better. Self-mutilation is frequently associated with relief of tension and enhanced mood (Brain et al. 1998). This may provide some explanation for menstrual exacerbations in these behaviours. Another possibility is that menstruation represents a passive, frightening and unpredictable occurrence for these individuals, over which they have no control. Selfmutilation allows some control to be regained. Menstrual synchrony is a well-established phenomenon and may explain the apparent association of self-mutilating behaviour and menstruation (Weller et al. 1999).

Other factors may account for a relationship between the menstrual cycle and suicidal behaviour. Fear of pregnancy after delayed menstruation, psychological gender issues or emotional instability could all influence mood and stress and thus suicidal behaviour. Blum et al. (1992) found that adolescents who had sexual intercourse were significantly more likely to be at risk of suicide. Birtchnell \& Floyd (1975) reported a significantly higher proportion of female suicide attempters who were beyond the date of the next expected menstrual period, and that attempters within this category tended to be young and unmarried.
While it is difficult to draw firm conclusions from much of the literature reviewed here because of the diversity of methods used, studies with better methodology suggest a positive relationship between aspects of the menstrual cycle and non-fatal suicidal behaviour. Such behaviour appears to be more common in those phases of the menstrual cycle when the oestrogen levels are lowest. The discrepancy of approximately one-third between hormonal measurement and patient reporting found by Baca-Garcia et al. (2000) may account for the contradictory findings in other studies. At present there appears to be no convincing evidence that suicide is related to menstrual cycle phase, but the practicalities involved in conducting a study to fully investigate this are complex.

The strongest correlation between menstrual cycle and suicidal behaviour appears to be in those who suffer from the PMS. In this group there is strong evidence that SSRIs are an effective treatment in reducing both behavioural and psychological symptoms of PMS, although no study made specific reference to suicidal behaviour.

Possible mechanisms for a relationship between the menstrual cycle and suicidal behaviour seem likely to involve interaction between oestrogen levels and the serotonergic system. The lower serotonin levels associated with low oestrogen phases of the cycle may act as a precipitating factor in those women already predisposed to suicidal behaviour.

Further studies using multiple hormone measurement to determine cycle phase and larger sample sizes are required. Clear definition of the suicidal behaviour being analysed is essential in combination with objective scales for measurement of suicidal intent.

Careful assessment of individual cases may indicate whether there may be an association between self-harm or suicidal thoughts and menstrual cycle phase and indicate where specific clinical interventions might be helpful. Awareness of the cycle phase may help the patient, family and health professionals prepare for worsening symptoms and take any necessary action. Furthermore, the knowledge that this is the reason for the worsening of symptoms (and that they will improve again) may help the patient to cope. 


\section{ACKNOWLEDGEMENTS}

We thank Professor J. Bancroft, Professor D. Kohen, Dr M. Linehan, Dr J. Sinclair, Dr M. Steiner and Professor R. Wetzel for their advice and assistance.

\section{DECLARATION OF INTEREST}

None.

\section{REFERENCES}

Abramowitz, E. S., Baker, A. \& Freischer, S. F. (1982). Onset of depressive psychiatric crises and the menstrual cycle. American Journal of Psychiatry 139, 745-748

Babin, E. (1933). Der Selbstmord der Frau in Beziehung zur Menstruation und Gravidität. Bleucher Druckerei: Breslau.

Baca-Garcia, E., Diaz-Sastre, C., Ceverino, A., Garcia Resa, E., Oquendo, M. A., Saiz-Ruiz, J. \& de Leon, J. (2004). Premenstrual symptoms and luteal suicide attempts. European Archives of Psychiatry and Clinical Neuroscience 254, 326-329.

Baca-Garcia, E., Diaz-Satre, C., Ceverino, A., Saiz-Ruiz, J., Diaz, F. J. \& de Leon, J. (2003a). Association between the menses and suicide attempts: a replication study. Psychosomatic Medicine $\mathbf{6 5}$, 237-244.

Baca-Garcia, E., Diaz-Satre, C., de Leon, J. \& Saiz-Ruiz, J. (2000). The relationship between menstrual cycle phases and suicide attempts. Psychosomatic Medicine 62, 50-60.

Baca-Garcia, E., Sanchez-Gonzalez, A., Gonzalez Diaz-Corralero, P., Gonazalez Garcia, I. \& de Leon, J. (1998). Menstrual cycle and profiles of suicidal behaviour. Acta Psychiatrica Scandinavica 97, $32-35$.

Baca-Garcia, E., Vaquero, C., Diaz-Sastre, C., Ceverino, A., SaizRuiz, J., Fernandez-Piquera, J. \& de Leon, J. (2003b). A pilot study on a gene-hormone interaction in female suicide attempts. European Archives of Psychiatry and Clinical Neuroscience 253, 281-285.

Beck, A. T., Herman, I. \& Schuyler, D. (1974a). Development of suicidal intent scales. In The Prediction of Suicide (ed. A. T. Beck, H. L. P. Resnik and D. J. Lettieri), pp. 45-56. Charles Press: Bowie, MD.

Beck, R. W., Morris, J. B. \& Beck, A. T. (1974b). Cross validation of the suicidal intent scale. Psychological Reports 34, 445-446.

Birtchnell, J. \& Floyd, S. (1974). Attempted suicide and the menstrual cycle: a negative conclusion. Journal of Psychosomatic Research 18, 361-369.

Birtchnell, J. \& Floyd, S. (1975). Further characteristics of suicide attempters. Journal of Psychosomatic Research 19, 81-85.

Blum, R. W., Harmon, B., Harris, L., Bergeisen, L. \& Resnick, M. D. (1992). American Indian-Alaska Native youth health. Journal of the American Medical Association 267, 1637-1644.

Bourgeois, M., Pedariosse, A. M., Degeilh, B. \& Dartigues, J. F. (1987). Impact of the pre- or perimenstrual period and syndrome on suicidal behavior. Survey of 127 women who attempted suicide. Annales Medico-Psychologiques (Paris) 145, 429-438.

Brain, K. L., Haines, J. \& Williams, C. L. (1998). The psychophysiology of self-mutilative behaviour: evidence of tension reduction. Archives of Suicide Research 4, 227-242.

Buckle, R. C., Linnane, J. \& McConachy, N. (1965). Attempted suicide presenting at the Alfred Hospital, Melbourne. Medical Journal of Australia 1, 754-758.

Carter, D. A., McGarrick, G. M., Norton, K. R., Paykel, E. S., Prysor-Jones, R. A. \& Whitehead, S. A. (1982). The effect of chronic neuroleptic treatment on gonadotrophin release. Psychoneuroendocrinology 7, 201-207.
Caykoylu, A., Capoglu, I. \& Ozturk, I. (2004). The possible factors affecting suicide attempts in the different phases of the menstrual cycle. Psychiatry and Clinical Neuroscience 58, 460-464.

Chaturvedi, S. K., Chandra, P. S., Gurauraj, R., Pandian, D. R. \& Benna, M. B. (1995). Suicidal ideas during the premenstrual phase. Journal of Affective Disorders 34, 193-199.

Clare, A. W. (1983). Psychiatric and social aspects of premenstrual complaints. Psychological Medicine. Monograph Supplement 4, $1-58$.

Craik, E. M. (ed. and trans.) (1998). Hippocrates: Places in Man. Clarendon Press: Oxford.

Dalton, K. (1959). Menstruation and acute psychiatric illnesses. British Medical Journal 17, 148-149.

Eckeberg, O., Jacobsen, D., Sorum, Y. \& Aass, G. (1986). Self poisoning and the menstrual cycle. Acta Psychiatrica Scandanavica 73, 239-241.

Elo, O. (1931). Suicide and suicides in Finland [in German]. Deutsche Zeitschrift fuer die Gesamte Gerichtliche Medizin 17, 348.

Endicott, J. \& Halbreich, U. (1988). Clinical significance of premenstrual dysphoric changes. Journal of Clinical Psychiatry 49, 486-489.

Englander-Golden, P., Whitmore, M. \& Dienstbier, R. (1978) Menstrual cycle as a focus of study and self-report of moods and behaviour. Motivation and Emotion 2, 75-86.

Esquirol, E. (1885). A Treatise on Insanity (translated from the French, with additions, by E. K. Hunt), pp. 184-185. Lea and Blanchard: Philadelphia.

Fludder, J. M. \& Tonge, S. R. (1975). Variations in the concentrations of monoamines and their metabolites in eight regions of rat brain during the oestrous cycle: a basis for interactions between hormones and psychotropic drugs. Journal of Pharmacy and Pharmacology 27 (Suppl.), 39.

Forestié, V., De Lignières, B., Roudot-Thoraval, F., Fulli-Lemaire, I., Cremniter, D. \& Nahoul, K. (1986). Suicide attempts in hypoestrogenic phases of the menstrual cycle. Lancet 2, 1357-1360.

Freud, S. (1974 [1883-1895]). Studies on hysteria. In The Standard Edition of the Complete Psychological Works of Sigmund Freud, vol. II. Hogarth Press: London.

Gisselmann, A., Ait Ameur, A., Pinoit, J. M., Francois, I. \& Trapet, P. (1996). Attempted suicide and menstrual cycle. An epidemiologic study. Annales Medico-Psychologiques (Paris) 154, 136-139.

Glass, G. S., Heninger, G. R., Lansky, M. \& Talan, K. (1971). Psychiatric emergency related to the menstrual cycle. American Journal of Psychiatry 128, 705-711.

Golub, S. \& Harrington, D. (1981). Premenstrual and menstrual mood changes in adolescent women. Journal of Personality and Social Psychology 41, 961-965.

Grinsted, J., Jacobsen, J. D., Grinsted, L., Schantz, A., Stenfoss, H. H. \& Nielsen, S. P. (1989). Prediction of ovulation. Fertility and Sterility 52, 388-393.

Hawton, K., Hall, S., Simkin, S., Bale, L., Bond, A., Cod, S. \& Stewart, A. $(2003 a)$. Deliberate self-harm in adolescents: a study of characteristics and trends in Oxford, 1990-2000. Journal of Child Psychology and Psychiatry 44, 1191-1198.

Hawton, K., Harris, L., Hall, S., Simkin, S., Bale, E. \& Bond, A. $(2003 \mathrm{~b})$. Deliberate self-harm in Oxford, 1990-2000: a time of change in patient characteristics. Psychological Medicine 33, 987-995.

Heller, A. (1900). A study of suicide based on 300 autopsies [in German]. Munchener Medizinische Wochenschrift 47, 1653-1658.

Helweg-Larsen, K. \& Hestbech, J. (1985). Deaths due to suicide and accidents in relation to menstrual cycle. Ugeskrift for Laeger 147, 318-321.

Holding, T. A. \& Minkhoff, K. (1973). Parasuicide and the menstrual cycle. Journal of Psychosomatic Research 17, 365-368.

Hollander, E. \& Stein, D. (eds) (1995). Impulsivity and Aggression. John Wiley \& Sons: New York.

Jannone, D. (1962). Suicide and attempted suicide in relation to the menstrual cycle [in Italian]. Policlinico: Sezioni Practica 69, 1144-1150. 
Janowsky, D. S., Gorney, R. \& Mandell, A. J. (1967). The menstrual cycle: psychiatric and ovarian-adrenocortical hormone correlates: case study and literature review. Archives of General Psychiatry 17, 459-469.

Joffe, J. \& Cohen, L. S. (1998). Estrogen, serotonin, and mood disturbance. Where is the therapeutic bridge? Biological Psychiatry 44, 798-811.

Kessler, R. C., McGonagle, K. A., Swartz, M., Blazer, D. E. \& Nelson, C. B. (1993). Sex and depression in the National Comorbidity Survey I: lifetime prevalence, chronicity and recurrence. Journal of Affective Disorders 29, 85-96.

Keye, W. R., Hammond, D. C. \& Strong, T. (1986). Medical and psychological characteristics of women presenting with premenstrual symptoms. Obstetrics and Gynaecology 68, 634-637.

Luggin, R., Bernsted, B., Petersson, B. \& Jacobsen, A. T. (1984). Acute psychiatric admission related to the menstrual cycle. Acta Psychiatrica Scandanavica 69, 461-465.

MacKinnon, I. L., MacKinnon, P. C. B. \& Thompson, A. D. (1959). Lethal hazards of the luteal phases of the menstrual cycle. British Medical Journal 46, 1015-1017.

MacKinnon, P. C. B. \& MacKinnon, I. L. (1956). Hazards of the menstrual cycle. British Medical Journal 1, 555.

Malone, K. M., Corbitt, E. M., Li, S. \& Mann, J. J. (1996). Prolactin response to fenfluramine and suicide attempt lethality in major depression. British Journal of Psychiatry 168, 324-329.

Mandell, A. J. \& Mandell, M. P. (1967). Suicide and the menstrual cycle. Journal of the American Medical Association 9, 792-793.

Mann, J. J. (1998). The neurobiology of suicide. Nature Medicine 4, 25-30.

McEwen, B. S., Alves, S. E., Bulloch, K. \& Weiland, N. G. (1997). Ovarian steroids and the brain: implications for cognition and aging. Neurology 48, S8-S15.

Moos, R. (1969). Typology of menstrual symptoms. American Journal of Obstetrics and Gynecology 103, 390-402.

Nolen-Hoeksema, S. (1987). Sex differences in unipolar depression: evidence and theory. Psychological Bulletin 101, 259-282.

O'Carroll, P. W., Berman, A. L., Maris, R. W., Moscicki, E. K., Tanney, B. L. \& Silverman, M. (1996). Beyond the Tower of Babel : a nomenclature for suicidology. Suicide and Life Threatening Behaviours 26, 227-235.

O'Neil, M., Lancee, W. \& Freeman, J. (1984). Fluctuations in psychological distress during the menstrual cycle. Canadian Journal of Psychiatry 29, 373-378.

Pallis, D. J. \& Holding, T. A. (1976). The menstrual cycle and suicidal intent. Journal of Biosocial Sciences 8, 27-33.

Parvathi Devi, S. \& Venkoba Rao, A. (1972). The premenstrual phase and suicidal attempts. Indian Journal of Psychiatry 14, 375-379.

Peller, S. (1935). Menarche, menstruation and suicide [in German]. Wiener Medizinische Wochenschrift 85, 205-207.

Ribeiro, A. L. (1962). Menstruation and crime. British Medical Journal 1, 640-641.

Rosenthal, R. J., Rinzler, C., Wallsh, R. \& Klausner, E. (1972). Wrist-cutting syndrome: the meaning of a gesture. American Journal of Psychiatry 11, 1363-1368.

Sachwiz, A. (1927). Reasons for suicide [in German]. Deutsche Zeitschrift fuer die Gesamte Gerichtliche Medizin 10, 312-321.

Simpson, M. A. (1975). The phenomenonology of self mutilation in a general hospital setting. Canadian Psychiatric Association Journal 20, 429-434.

Slavik, W. (1909). Menstrual psychosis: its relationship to penal law and the frequency of suicides in women [in German]. Revue de Médecine Tchèque 2, 112-113.

Steiner, M. (1926). Menstruation and suicide [in German]. Deutsche Medizinische Wochenschrift 2120-2121.
Storer, H. R. (1864). Suicide during the catamential molimen. Boston Medical and Surgical Journal 70, 189-200.

Stout, S. B., Steege, J. F., Blazer, D. G. \& George, L. K. (1986). A comparison of lifetime psychiatric diagnoses in premenstrual syndrome clinic and community samples. Journal of Nervous and Mental Disorders 174, 517-521.

Sumner, B. E. H. \& Fink, G. (1995). Estrogen increases the density of 5-hydroxytryptamine $2 \mathrm{~A}$ receptors in cerebral cortex and nucleus accumbens in the female rat. Journal of Steroid Biochemistry and Molecular Biology 54, 15-20.

Targum, S. D., Caputo, K. P. \& Ball, S. K. (1991). Menstrual cycle phase and psychiatric admissions. Journal of Affective Disorders 22, 49-53.

Taylor, D. V., Rush, D., Hetrick, W. P. \& Sandman, C. S. (1993). Self-injurious behaviour within the menstrual cycle of women with mental retardation. American Journal of Mental Retardation 97, 659-664.

Taylor, J. (1979). The timing of menstruation-related symptoms assessed by a daily symptom rating. Acta Psychiatrica Scandanavica 60, 87-105.

Thompson, K., de Castella, A. \& Kulkarni, J. (1997). Psychotic women can estimate cycle phase as well as controls. Schizophrenia Research 23, 185-186.

Tonks, C. M., Rack, P. H. \& Rose, M. J. (1968). Attempted suicide and menstrual cycle. Journal of Psychosomatic Research 11, 319-323

Trautman, E. C. (1961). The suicidal fit. Archives of General Psychiatry 5, 98-105.

Uphouse, L., Williams, J., Eckols, K. \& Sierra, V. (1986). Cortical changes in serotonin receptors during the female rat estrous cycle. Brain Research 381, 376-381.

Vanezis, P. (1990). Deaths in women of reproductive age and relationship with menstrual phase, an autopsy study of cases reported to the coroner. Forensic Science International 47, 39-57.

Verkes, R. J., Asberg, M., Ven der Mast, R. C., Hengeveld, M. W., Tuyl, J. P., Zwinderman, A. H. \& Van Kempen, G. M. (1998). Reduction by paroxetine of suicidal behaviour in patients with repeated suicide attempts but not major depression. American Journal of Psychiatry 155, 543-547.

Vitali, M. L., Parisi, M. N., Chiocchio, S. R. \& Tramezzani, J. H. (1984). Median eminence serotonin involved in the proestrous gonadotrophin release. Neuroendocrinology 39, 136-141.

von Balazs, J. (1936). Menstruation and suicide [in German] Psychiatrisch-Neurologische Wochenschrift 38, 407-409.

Warner, P. \& Bancroft, J. (1990). Factors related to self-reporting of the pre-menstrual syndrome. British Journal of Psychiatry 157 249-260.

Weller, L., Weller, A. \& Roizman, S. (1999). Human menstrual synchrony in families and among close friends: examining the importance of mutual exposure. Journal of Comparative Psychology 113, 261-268.

Wetzel, R. D., Theodore, R. \& McClure, J. N. (1971). Phase of the menstrual cycle and self-referrals to a suicide prevention service. British Journal of Psychiatry 119, 523-524.

WHO (1999). The World Health Report. Geneva: World Health Organization.

Wyatt, K. M., Dimmock, P. W. \& O'Brien, P. M. S. (2003). Selective serotonin reuptake inhibitors for premenstrual syndrome (Cochrane Review). In The Cochrane Library, Issue 1. Update Software: Oxford.

Zacco, M., Pacilio, V., Piliego, N. \& Jannone, D. (1960). Suicide in relation to the menstrual cycle [in Italian]. Medicina Psicosomatica 5, 187-208. 